\title{
A CONSTRUÇÃO DE UMA CLÍNICA PSICANALÍTICA PARA MIGRANTES
}

\author{
Taeco Toma Carignato*
}

\begin{abstract}
O artigo objetiva o desenvolvimento de uma metodologia clínica que envolva a história e a política nos atendimentos a pessoas e grupos em deslocamento, marcados por profundas rupturas e outras experiências traumáticas. Debate a abordagem psicossocial que privilegia a escuta psicanalítica direcionada não somente aos emigrantes e imigrantes como também aos chamados "retornados", particularmente os decasséguis, cuja reinserção no país de origem é dificultada pelo estado de "suspensão" social e cultural em que se encontram devido às idas e vindas entre o país de origem e o de imigração. Procura também investigar os vários caminhos para a elaboração e a simbolização das experiências traumáticas dos deslocamentos humanos.
\end{abstract}

Palavras-chave: Decasségui; Retornado; Atendimento; Psicanálise; Trauma.

Uma sensação estranha apossou-se de mim naquela reunião com os brasileiros que estavam retornando do Japão. Não era uma sensação desagradável, mas estranha por ser insistente. Entre outros presentes, uma senhora chamou-me a atenção sem apresentar nada que pudesse caracterizála como diferente. "Devo tê-la conhecido em outra ocasião que não estou lembrando neste momento", pensei comigo mesma. Em ato contínuo, negava convictamente tal ideia: "Não, não a conheço". Em seguida, pegava-me novamente tentando lembrar onde a havia visto. No entanto, ela ficou quieta em seu lugar. Não fazia nenhum movimento diferente, não apresentava quaisquer características - sinais de depressão ou euforia, por exemplo - que pudessem fazer-me pensar em uma atenção especial.

\footnotetext{
* Psicanalista, doutora em Psicologia Social pela Pontifícia Universidade Católica de São Paulo e pósdoutora em Psicologia Clínica pela Universidade de São Paulo; membro do Laboratório Psicanálise e Sociedade (Instituto de Psicologia/USP) e do Núcleo de Pesquisa Psicanálise e Política (PUC-SP). E-mail: taecotoma@uol.com.br. São Paulo/Brasil.
} 
Nessa reunião, promovida pelo CIATE - Centro de Informação e Apoio ao Exterior, entidade da comunidade nipo-brasileira que normalmente atende pessoas interessadas em trabalhar no Japão, estavam as pessoas que retornavam. Elas relatavam suas experiências de vida e de trabalho naquele país, em uma evocação quase catártica que eu monitorava por meio da escuta e intervenções pontuais após pequeno discurso introdutório, geralmente interrompido pelos participantes. Nessa escuta, diferente da tradicional técnica psicanalítica ${ }^{1}$, a palavra circula, mas de maneira ordenada a fim de possibilitar que todos possam falar e escutar uns aos outros e a si mesmos.

Quando chegou a vez daquela senhora, não resisti e perguntei:

- "Já nos encontramos antes? Eu a conheço de algum lugar?"

Então, ela se abriu em um largo sorriso:

- "A senhora tratou de mim há sete anos."

Neste momento, uma profunda emoção tomou conta de mim:

- "Tomika!² Você está de volta! Como está?".

- "Muito bem!", respondeu enfaticamente. "Eu também não a havia reconhecido. Só percebi quem é você quando vi o seu nome". Ao dizer isso, apresentou o senhor que estava ao seu lado: Yoshio ${ }^{3}$, seu marido, um homem marcado pelas vicissitudes do trabalho no Brasil e no Japão, que também passou a me olhar com simpatia.

Deixando de lado os bloqueios psíquicos de ambos os lados, deixei-me invadir pela emoção do inesperado reencontro. Resumidamente, Tomika esclareceu que trabalhara junto com o marido mais sete anos após a crise paranoide 4 aguda que a acometera no Japão em seu primeiro período de migração e, agora, eles haviam retornado "para ficar". Estavam no Brasil há um ano. Informou que seus filhos já estavam formados e trabalhavam em suas respectivas profissões e ambos poderiam viver suas vidas tranquilamente perto deles. Afirmou que trabalhara bastante e que as crises não retornaram durante a sua segunda estada no Japão.

${ }_{1}$ A técnica psicanalítica da escuta privilegia a atenção flutuante do psicanalista, sem se deter em qualquer dos pontos da fala do analisando. "... consiste simplesmente em não dirigir o reparo para algo específico e em manter a mesma 'atenção uniformemente suspensa' (...) em face de tudo o que se escuta” (FREUD, Sigmunt. Recomendações aos médicos que exercem a psicanálise).

${ }^{2}$ Nome alterado.

${ }^{3}$ Nome alterado.

${ }^{4}$ Uso o termo paranoide em vez de paranoico, pois a crise de Tomika no Japão não tinha a ver com a estrutura psicótica. Não se tratava exatamente de uma psicose, embora tenha sido diagnosticada como portadora de transtornos paranoicos e estivesse medicada com Ziprexa, um antipsicótico. 
Quando a conheci, Tomika apresentava sintomas ligados a uma profunda angústia, após a remissão dos graves sintomas paranoides que a obrigaram a retornar ao Brasil. Os novos sintomas deixavam-na em uma agitação intensa, impedindo-a de dormir, mesmo com o uso de medicamentos. Era invadida por temores de que seus filhos seriam assaltados e sua filha estuprada. Ela mesma não conseguia andar sozinha pela cidade. Mas insistia em embarcar ao Japão. Já com passagem adquirida, queria juntar-se novamente ao marido, mas assim que marcou a data de embarque, a crise de angústia deflagrou-se.

Afirmava constantemente, logo na primeira entrevista: "Tenho de embarcar daqui a três semanas, mas perdi a coragem. Não sei o que está acontecendo. Nunca tive medo de nada, mas agora me falta coragem". E repetia, com bastante ênfase e continuamente: "Tenho de ir. Preciso ir. Meu marido está me esperando". Aparentemente era um recurso de autoconvencimento, como se a ênfase e a repetição pudesse fazê-la superar o que ela julgava como covardia. Insistia de que deveria "de qualquer maneira" embarcar dali a três semanas, senão perderia o prazo do visto de trabalho no Japão.

Tomika, no primeiro período de trabalho no Japão, permanecera naquele país por apenas dois anos - o prazo autodeterminado era de, pelo menos, cinco anos -, após ter ficado dez anos longe do marido, o qual decidira pela emigração para que os filhos pudessem estudar. Retornara ao Brasil várias vezes, por cansaço. Então estabeleceu com a Tomika um acordo: ela ficaria para cuidar dos filhos até eles entrarem na faculdade e, então, o acompanharia ao Japão e ambos trabalhariam até todos se formarem e o casal pudesse poupar o suficiente para a "aposentadoria".

Era evidente que, na ocasião do primeiro encontro - Tomika fora-me encaminhada por uma parente -, não tinha condições para embarcar. Ela mesma dizia estar com muito medo de que os sintomas paranoides que a haviam acometido no Japão retornassem assim que embarcasse. Mas insistia em viajar. Ao vê-la naquela situação de extrema angústia, dei-me conta apenas de que não poderia deixar de atendê-la, mesmo nos termos de sua exigência. Não tentei convencê-la sobre a impossibilidade de viajar ou fazer qualquer interpretação ou inferência que a fizesse ficar. Não mencionei qualquer probabilidade de melhora, apenas que deveria tratar-se mesmo que fosse naquele curto período que ela se determinava. $\mathrm{O}$ único recurso de que dispunha era escutá-la na transferência. ${ }^{5}$

\footnotetext{
Processo em que os desejos inconscientes passam a se repetir na relação analítica tendo como alvo a figura do analista. O que se manifesta na transferência não são apenas meras repetições de experiências passadas, mas equivalências simbólicas do que é transferido. Ou seja, o que o sujeito fala em situação de transferência vai além dos fatos. Traz toda a carga afetiva e traumática que lhe possibilitam a ressignificação das próprias experiências e dos próprios acontecimentos.
} 
Felizmente, a cunhada com a qual iria viajar ao Japão teve, por motivos próprios, de cancelar o embarque e, com isso, ganhamos algum tempo. Mesmo assim, o atendimento foi curto, embora intenso. Foram dois meses e meio de relatos não só a respeito das crises delirantes que a acometera no Japão, como também de sua infância, adolescência e casamento, sobre a emigração do marido e a solidão quando os filhos saíram de casa para estudar em outras cidades. O que me chamou a atenção, porém, foi que os relatos foram realizados com detalhes surpreendentes ${ }^{\mathbf{6}}$ sem apresentar resistências. Na transferência, Tomika começou a alcançar certa autonomia. Na terceira sessão, passou a vir sozinha ao meu consultório.

Após ouvir o relato sobre os sintomas paranoides, tomei a decisão de não me deter nessas recordações de sua vida no Japão e também de não relevar os sintomas que a estavam perturbando naquele momento, embora Tomika retornasse constantemente ao assunto. Conduzi as sessões de modo que ela falasse sobre a sua vida e a sua família, marcando os aspectos das experiências de migração, incluindo a de seus pais - Tomika é nissei (segunda geração) - e as da própria família em deslocamentos pelo interior do estado de São Paulo. Os deslocamentos em diversos níveis, inclusive o sociocultural, constituíram-se em sua herança familiar.

Em determinado momento, sem qualquer indício de que iria acontecer, as angústias desapareceram. Ao mesmo tempo em que comparecia às sessões, Tomika frequentava várias igrejas diferentes, na tentativa de se livrar dos sintomas ${ }^{7}$. Em uma delas, um atendente religioso tornou os sintomas mais agudos, levando-me a buscar a anulação da intervenção religiosa, tomando o cuidado de não me colocar em posição preconceituosa e anti-religiosa. Minha posição nessa área era ambígua: nem sim, nem não. Acompanhava seus movimentos e tentava articulá-los ao seu discurso.

Até que, em outra igreja, a pessoa que a atendeu disse-lhe que os sintomas derivavam do fato de que, no Japão, ela se "afastara de Deus". Tomika não era propriamente religiosa, mas encontrou um sentido no que

6 As ideias persecutórias impressionavam pelos detalhes e pelo fato de Tomika ter claras recordações de todo o processo delirante. Lembrou-se de que, no ápice, até pensou em sair por uma janela do apartamento onde morava, no terceiro andar, para escapar dos perseguidores. A idéia persecutória, no início, centrava-se em um colega de trabalho e depois foi tornando-se difusa e atribuída à máfia japonesa (yakuza). Na viagem de volta ao Brasil, Tomika imaginava que os mafiosos estariam a bordo e a qualquer momento retirariam cordas de suas bolsas para amarrá-la e atirá-la fora pela janelinha da aeronave. Ela mesma reconheceu o absurdo de seus pensamentos: "Imagine! Como eu poderia passar por aquelas janelinhas do avião?".

7 Tomika frequentava simultaneamente diferentes religiões na tentativa de se livrar dos sintomas. Em uma ocasião, a intervenção de um "consultor" religioso tornou os sintomas mais agudos, levandome a tentar "desmanchar" o mal-estar provocado tomando o cuidado de não me colocar em posição preconceituosa ou anti-religiosa. 
ela passou a afirmar: "Eu me afastei de Deus. Fiquei suspensa. Meu Deus, perdi o chão no Japão". Havia uma ligação destas frases com os sintomas paranoides $^{8}$ e, embora ela não os tenha associado verbalmente, com essa ligação o mal-estar desapareceu. Tomika sentiu-se fortalecida e embarcou alguns dias depois.

Após a sua partida, fiquei me perguntando se as crises não retornariam durante a viagem ou quando começasse a trabalhar no Japão, pois os primeiros focos das ideias persecutórias foram investidos nos colegas de trabalho. No entanto, Tomika voltou para a mesma fábrica onde trabalhara, retomando a sua vida no Japão, período em que se realizou como trabalhadora assalariada. ${ }^{9}$ Não significa que ela tivesse curado suas neuroses. O retorno ao Brasil poderia ter sido outro marco para o ressurgimento dos sintomas, mas ela e o marido já estavam há um ano no Brasil.

Sete anos depois. Ao terminar a reunião no CIATE, Tomika abraçoume ao se despedir. Seu marido também veio cumprimentar-me. Não disse nada, mas seu olhar transmitia: "Obrigado por ter cuidado de minha mulher". Depois desse reencontro, não mais a vi e nem tive notícias suas. Este caso foi emblemático e fez-me pensar em uma clínica que relevasse a escuta e a transferência no atendimento aos migrantes, imigrantes e refugiados, pensando nas incidências psíquicas dos deslocamentos humanos, bem como na inclusão dos fundamentos sociais, culturais e políticos nos processos de transferência.

\section{A clínica psicanalítica nos deslocamentos}

É um desafio. Desenvolver uma metodologia que envolvesse o social e a política com base em uma tradicional teoria psíquica conhecida pela prática individualizada e de longa duração visando atender pessoas marcadas por profundas e, por vezes, violentas rupturas e mobilizadas em constantes deslocamentos. Essa modalidade de atendimento deve levar em conta a história e a política associadas às singularidades subjetivas da pessoa, grupo e/ ou populações atendidas, cujo principal instrumento é a escuta psicanalítica na transferência.

Permito-me escrever este texto com base em minha singularidade, dadas as minhas experiências no processo de formação psicanalítica, nos

\footnotetext{
8 Não é incomum a idéia de "suspensão" entre os imigrantes que não são integrados na sociedade de recepção. Comecei a pensar se determinados suicídios ou tentativas de suicídio (em direção ao vácuo) que ocorrem nos processos de deslocamento não decorreriam da idéia de suspensão.

9 Tomika trabalhou durante toda a sua vida, mas a primeira vez que recebeu salários mensais regulares foi no Japão, com o trabalho operário. Sentia-se feliz "por ter um dinheiro no bolso" e poder comprar o que the agradasse sem que fosse destinado aos filhos ou culpada por gastar o dinheiro ganho com tantos sacrifícios pelo marido.
} 
atendimentos clínicos e psicossociais, nos estudos e nas reflexões sobre a migração. Desenvolvi estas experiências no atendimento aos usuários da Casa do Migrante, em um projeto de extensão do Instituto de Psicologia da Universidade de São Paulo e nos trabalhos realizados no Centro de Informação e Apoio ao Exterior (CIATE) dedicado aos trabalhadores brasileiros no Japão, no Projeto Kaeru do Instituto de Solidariedade Educacional e Cultural (ISEC) e na minha clínica particular. Além das articulações com outros diferentes projetos e instituições.

Nos atendimentos individuais ou coletivos aos migrantes e refugiados, devemos sempre pensar em questões que vão além das singularidades e subjetividades, porém sem descartá-las. Preocupação constante da Psicologia Social, o desafio de se pensar a relação indivíduo/sociedade, singular/coletivo, individual/social ganhou novas referências com o auxílio da psicanálise que, nascida na Europa Central, adquiriu novos contornos em nações das Américas, constituídas no passado e no presente por deslocados em todos os níveis, dos altos executivos aos trabalhadores não qualificados, passando pelos camponeses e pelos afrodescendentes.

A psicanálise não poderia ignorar a política, a cultura e a sociedade, diferentemente de seu desenvolvimento na Europa, cujas sociedades, em cada uma de suas respectivas nações, buscaram uma identidade nacional a partir de grupos, sociedades e pensamentos hegemônicos. Tanto assim, que chamamos de "psicanálise inglesa" a que possui fortes influências de Melanie Klein, Wilfred Bion e Donald Winnicott, e "psicanálise francesa", a gerada por Jacques Lacan. Apesar de migrar de país a país, de sociedade a sociedade, de cultura a cultura, a psicanálise manteve-se como pensamento e prática singulares, centrando-se no indivíduo universalizado pela sua constituição como sujeito dividido entre a consciência e o inconsciente.

E foi assim que ela chegou à "América" ou, mais precisamente, aos Estados Unidos, conduzida pelo próprio fundador, Sigmund Freud, em 1909. Popularizada nos Estados Unidos, a cultura que a envolveu cobriu e encobriu a prática analítica com o objetivo economicista que se expandiu no solo estadunidense. O grupo, a sociedade e o povo adquiriram o caráter semelhante ao do indivíduo instado a competir com o outro em constante busca da supremacia. O embate pela supremacia econômica e política enveredou para a cultura, a ponto de, no embate entre o Ocidente e o Oriente (que se desdobrou geograficamente), chegar à deplorável ideia de "choque de civilizações".

$\mathrm{Na}$ tentativa de redimir o outro diferente, colocado na posição de selvagem ou primitivo, a cultura ocidental elevou-o à condição de "civilização", sem, porém, abolir as iniquidades e a dominação econômica, 
social e política. Suspenso na categoria de "civilizado" o outro diferente é ao mesmo tempo considerado inferior, cidadão de segunda classe e, às vezes, até "desclassificado" (sem possibilidade de pertencer a nenhuma classe social). Nos tempos atuais, nas questões referentes à migração, os problemas gerados pela discriminação, preconceito e exclusão são interpretados como "choques culturais".

Será mesmo que se trata de "choques culturais" o estranhamento, a recusa à cultura hegemônica, a resistência à aprendizagem da língua do país receptor? Será que se derivam de "choques culturais" a auto-clausura, a recusa à cultura de origem, a dificuldade em se expressar na língua materna e de se inserir no trabalho e na sociedade que já conheceram?

Como atuar com a problemática teórica e metodológica no atendimento aos migrantes e aos refugiados? No caso dos refugiados, além do histórico de violências e experiências traumáticas, deparamo-nos não só com as profundas diferenças culturais, mas também com o desconhecimento total das línguas de origem, algumas delas dialetos muito específicos. Há o recurso do emprego do tradutor nos atendimentos, recurso utilizado em países multiculturais, como o Canadá. ${ }^{10}$ Só a temática da tradução envolveria um prolongado estudo, de forma que não a abordarei neste artigo.

A prática clínica que desenvolvo com imigrantes e com aqueles que estão retornando envolve atendimentos individuais e em grupo, em diferentes contextos, apesar de se tratar de pessoas com experiências de migração muito semelhantes. Os participantes têm consciência do atual fenômeno da migração que os pesquisadores denominam como "movimento pendular"11. Porém, tal circularidade envolvendo o Brasil e Japão, embora considerada prejudicial pelos pesquisadores por acentuar a desfiliação, não Ihes parecia despropositada e prejudicial. Justificam-na como necessária para o descanso, tratamento de saúde e recuperação de energia, após prolongadas e desgastantes jornadas de trabalho.

Nos atendimentos, atuo em instituições e na clínica particular. No projeto de atendimento a imigrantes e refugiados que os Núcleos Psicanálise e Sociedade (USP) e Psicanálise e Política (PUC-SP) realizam na Casa do Migrante, atualmente fico no apoio e suporte. No Projeto Kaeru, dedicado ao atendimento direto em escolas públicas do ensino fundamental às crianças

\footnotetext{
${ }^{10}$ Jean-Bernard Pocreau, Professor da Universidade de Laval, dirige um Centro de Terapia para imigrantes e refugiados em Quebec, Canadá.

${ }^{11}$ Beltrão e Sugahara verificaram em 2004 que 41\% dos seus entrevistados haviam ido ao Japão mais de uma vez (cf. NAKAMOTO, Ana Luisa Campana. De volta para casa: um estudo sobre brasileiros e brasileiras retornados do Japão, p. 49).
} 
e adolescentes que retornam do Japão, dedico-me à atenção aos pais e apoio às oficinas para facilitar a inserção dos adolescentes no ambiente cultural brasileiro.

Todas essas experiências são muito ricas, mas vou me dedicar mais ao trabalho que desenvolvo desde 2005 no CIATE. Uma vez por mês, atendo grupo de pessoas que procuram o CIATE, por motivos diversos. Aqueles que desejam emigrar buscam informações sobre documentação, trabalho e cultura no Japão, e os que retornam querem saber a respeito de resgate dos impostos e das contribuições pagos no Japão. Mas o interesse principal para uns e para outros está, principalmente, na situação do emprego, aqui ou lá.

O CIATE foi criado em 1992 pela comunidade nipo-brasileira de São Paulo para atender os brasileiros que emigravam ao Japão. Com palestras ministradas por diferentes profissionais, procurava-se preparar o candidato a empregos no Japão, fornecendo informações sobre as leis trabalhistas, os seguros sociais (seguros de desemprego, acidente de trabalho, saúde e previdência) e os costumes daquele país. Hoje, a entidade também fornece cursos básicos de língua japonesa, procurando preparar o candidato a, pelo menos, falar e compreender a linguagem do trabalho em fábricas e serviços, para onde é encaminhada a maioria dos imigrantes brasileiros no Japão. ${ }^{12}$

A mim coube o que a entidade considerou como "preparação psíquica" para a emigração. As questões psíquicas não fazem exatamente parte do programa de atividades da entidade, voltada mais para o campo do trabalho. Entretanto, a coordenadora do curso entende ser necessária esta atuação, devido às pessoas psiquicamente perturbadas que compareciam à entidade, e abriu um espaço para o trabalho com psicólogos e psiquiatras para abordar as questões de saúde, particularmente de saúde mental. Eram muitos os problemas de saúde registrados entre os brasileiros no Japão por excesso de trabalho e dificuldades de adaptação ao país.

Em princípio, a atividade seria desenvolvida na forma de palestras educativas, mas percebendo a inutilidade do discurso preparado - pois poucos escutam aquilo que não querem ouvir, principalmente sobre os riscos de um empreendimento pessoal que envolve os deslocamentos -, aproveitei o espaço para dar a palavra aos emigrantes e, posteriormente, aos que retornaram. Após as primeiras experiências com oficinas utilizando colagem e outras técnicas de atividade grupal, optei apenas pela palavra ao verificar a necessidade de os participantes exporem suas dúvidas, receios, esperanças e outros sentimentos.

${ }^{12}$ CIATE. Vinte anos de História. 
A circulação da palavra tem a sua eficácia na produção de laços sociais, mesmo entre aqueles que estavam prestes a romper os vínculos afetivos com o lugar de origem. Eu não tinha exatamente a intenção de "preparar" pessoas para o trabalho no Japão ou à emigração, mas possibilitar um canal de comunicação constante com o país que estavam deixando e, ao mesmo tempo, incentivá-las ao esforço pela integração na sociedade, na cultura e no país ao qual estavam se destinando.

Nesse sentido, passei a considerar o que o CIATE chamou de "preparação psíquica" para o trabalho no exterior como reflexão sobre os significados da emigração e do luto de separação. Pois emigrar envolve, fundamentalmente, rupturas. Rupturas em todos os níveis: pais e mães emigrantes separam-se de filhos, filhos separam-se de pais e irmãos, marido separa-se mulher e filhos, mulher separa-se do marido e dos filhos. Sem falar nas rupturas linguísticas, culturais, sociais e profissionais. Tudo isso exige um trabalho de luto que pode ser realizado de diferentes formas, permitindo-nos incluir no nosso cotidiano a significação das perdas e da falta.

Passei também a considerar também como "preparação psíquica" para a emigração a reflexão sobre o tempo do migrante, um tempo específico marcado por rupturas e ausências. O sujeito que emigra torna-se sujeito de uma ausência: o lugar que ocupa na sociedade de origem não é eliminado como acontece com a morte de um familiar. Nem é preenchido ou substituído, pois o emigrante continua lá, vivo mesmo que não envie notícias, porém envolvido pelo espectro da ausência. Entendia que deveria alertá-los sobre o retorno, ou mais exatamente, sobre a impossibilidade do retorno à origem, pois entre a ida e o retorno, há a passagem do tempo, esse complexo tempo do migrante. A pessoa que retorna, no mínimo, volta com alguns (ou muitos) anos a mais.

Fundamentalmente, procurava pensar como o sentido da migração comporta o desejo e o seu deslocamento. Em psicanálise, o sujeito é marcado por uma perda fundamental que institui a falta e mobiliza o desejo por meio do qual ele empreende a jornada em busca de respostas. Nesse sentido, o desejo sempre se desloca na medida em que as respostas e os objetos com os quais procura preencher e abolir a falta nunca serão suficientes. Quando os deslocamentos do desejo não operam no simbólico, o sujeito se põe em marcha, buscando caminhos diversos, sempre se deslocando fisicamente.

No CIATE, em um encontro mensal, não era possível trabalhar o que julgava necessário. Então, centrei-me no debate sobre o sentido e o desejo de emigrar. Evitei qualquer questionamento sobre as condições dos candidatos ao trabalho no Japão para a emigração, pois isso seria mais um "empurrão" 
para os deslocamentos. Era inútil a tentativa de conscientizá-los sobre as vicissitudes relativas às mudanças de país, de língua e de cultura, pois eles vinham determinados a emigrar ou reemigrar. Procurava, então, torná-los cientes da existência de um desejo responsável pelos deslocamentos psíquicos, sociais e geográficos. Responsável principalmente pela repetição. Com isso, buscava fazê-los pensar também sobre o sentido de "trabalhar no Japão".

A resposta a essa questão era imediata: "Ganhar dinheiro". Evidentemente, em toda migração espontânea, "dinheiro" é o significante primordial. Mais que trabalho. Quando eu argumentava que "também se trabalha no Brasil", o contraponto era imediato: "Mas não se ganha tanto dinheiro!" Havia ainda a questão da dívida. De fato, homens e mulheres na faixa de 40 e 50 anos (ou mais), desempregados, buscavam trabalho no Japão para saldarem suas dívidas. Mulheres separadas esperavam ganhar o suficiente para manter ou pagar estudos para os filhos que deixavam com seus genitores. Homens e mulheres aposentados sonhavam encontrar nova vida.

Jovens recém-formados de cursos superiores emigravam para ganhar dinheiro rápido e "comprar casa", mesmo sabendo que, no máximo, conseguiriam apenas o suficiente para comprar um carro. Argumentavam que os salários pagos no Brasil eram insuficientes para arcar as despesas com o aluguel, os estudos e o lazer. Diziam que planejavam ter moradia própria, mas não queriam contrair uma dívida de 15 ou mais anos para pagar uma casa ou apartamento. Na verdade, encobriam o desejo de consumo: o carro era (ainda é) um poderoso objeto (alienado) do desejo.

Entre outros, apareciam também os jovens egressos do ensino médio que buscavam "juntar dinheiro" para pagar cursinho e/ou faculdade no regresso. Sem qualificação e experiência, tinham dificuldades para encontrar trabalho com o qual pudessem manter-se e estudar. Aqueles que se sentiam confusos sobre qual caminho a seguir (faculdade ou trabalho?) e eram pressionados pelos familiares para trabalhar e/ou estudar, buscavam a solução de seus conflitos familiares na emigração.

Evitava avaliar ou discutir se os candidatos estavam aptos ou não a emigrar. Eles queriam emigrar e pronto. Nada os demoveria da ideia. Alguns já haviam trabalhado no Japão e procuravam informar-se e preparar-se para uma nova emigração. Não se mostravam esperançosos ou desiludidos, mas conformados: o trabalho no Japão era a única saída. Os encontros foram ganhando uma nova dimensão: os emigrantes faziam uso de sua voz sem medo de reprovações e valiam-se das experiências dos participantes que já estavam em sua segunda ou terceira emigração. Estes, por sua vez, sentiam-se confortados ao serem escutados pelos seus pares. 
Não há dados específicos sobre os atendimentos no CIATE. A própria entidade não é precisa na divulgação dos dados em seus boletins anuais. Também não tomei nota dos meus atendimentos. Mas desde o início também compareciam os retornados, não somente os candidatos a emprego no Japão. Nos primeiros anos, vinham em pequeno número, mas a partir da crise econômica de 2008, o terremoto, o tsunami e os riscos de radiação ocorridos em março de 2011, a quantidade foi aumentando a ponto de os grupos se constituírem quase que exclusivamente de retornados.

\section{Crise econômica e tsunami}

Não há dados de quantos brasileiros retornaram do Japão após a crise, a não ser uma estimativa obtida pelas diferenças dos registros de brasileiros residentes naquele país. Entre 2008 e 2012, a diferença foi de, aproximadamente, 106.935 pessoas, segundo o Ministério da Justiça do Japão. Não significa que todas essas pessoas retornaram e permaneceram no Brasil. Muitas, por não se adaptarem no país de origem, foram novamente em busca de trabalho no Japão apesar de todas as informações que circulavam na mídia sobre a crise de desemprego naquele país. As idas e vindas entre Brasil e Japão continuaram e, com a formação de redes sociais de imigrantes brasileiros naquele país, os que ainda desejam emigrar já não buscam os serviços do CIATE, a não ser em casos específicos.

Além do CIATE, também atua na recepção dos retornados o Niatre - Núcleo de Informação e Apoio aos Trabalhadores no Exterior, que faz a intermediação para a recolocação no mercado de trabalho. Passaram a atender as pessoas que desejam informações sobre documentação com vistas ao resgate de pagamentos ao seguro social e previdenciário realizados no Japão e contatos para empregos no Brasil. Com pouca estrutura de atendimento, o Niatre, porém, não consegue atender às necessidades dos brasileiros que retornam, necessidades que não se resumem à busca de trabalho.

Os primeiros atendimentos foram impactantes. O Niatre foi chamado pela Santa Casa de Misericórdia para resolver o caso de um retornado que falecera na instituição, durante uma internação. As únicas informações que a instituição possuía eram de um passaporte. Provavelmente, ao chegar muito doente do Japão fora encaminhado para a Santa Casa, onde faleceu. Depois de muitas consultas e articulações nos consulados, no Brasil e no Japão, o Niatre localizou a esposa do falecido, que tomou as providências necessárias.

Outra situação envolveu um rapaz de 30 anos, recém-chegado do Japão, com nacionalidade brasileira, mas sem falar nada em português. Emigrara com os pais ainda criança ao Japão, estudando sempre em escolas 
japonesas. Buscando contatos, descobriu que ele tinha uma tia residindo no Brasil a qual, no entanto, recusou-se a recebê-lo e a ajudá-lo no seu sustento. Na base de contribuições, o Niatre instalou-o em uma pensão e providenciou-Ihe o fornecimento de cestas básicas. Também Ihe conseguiu emprego em um restaurante japonês, por meio do qual o recém-chegado passou a pagar a pensão. É possível que, pelas suas reticências e a recusa dos parentes em recebê-lo, ele tivesse sido deportado após cumprir pena no Japão. Mas nada foi dito e mesmo os técnicos do CIATE preferiram ignorar o motivo de sua inesperada chegada.

O número e a situação dos brasileiros que retornam do Japão, porém, ainda são desconhecidos. O Niatre registrou no seu balanço de atendimentos, no período de janeiro a novembro de 2011, apenas 948 consulentes. É um número muito pequeno diante da estimativa dos retornados. Eles se espalham pelo país em suas respectivas cidades de origem, muitas vezes sem se identificarem como retornados. Apenas os parentes próximos sabem de sua passagem pelo Japão. Evitam falar sobre as experiências no Japão até para os familiares. Só se sentem à vontade para falar da vida no Japão quando se reúnem com outros retornados.

Em São Paulo, os retornados espalham-se pelos bairros e a sua localização também é bastante difícil, mesmo para o Projeto Kaeru, que se dedica ao atendimento das crianças e dos adolescentes com o apoio da Fundação Mitsui Bussan. Os técnicos do Projeto precisam fazer verdadeira "garimpagem" em escolas das redes municipal e estadual de ensino para localizar as crianças e seus pais. As entidades da comunidade nipo-brasileira paulistana, as chamadas kenjin-kais (entidades representativas de províncias japonesas) não oferecem nenhum programa de acolhimento e apoio aos retornados. No entanto, frequentando algumas atividades culturais dessas instituições, pode-se verificar que muitas famílias estão recebendo parentes que retornam do Japão. Mas estes permanecem reclusos em suas residências e, quando circulam pelas associações, não se identificam como tais.

Os familiares não falam, as entidades não se manifestam e os líderes comunitários ignoram. Pois falar de retornados significa falar de problemas, de conflitos pessoais e familiares muito intensos. Falar de "retorno" significa falar de decepções, desilusões, desgastes emocionais e frustrações. A maior parte daqueles que emigraram para "ganhar dinheiro", "buscar vida nova", "conhecer outro país", "ter novas experiências", conseguiu alcançar seus propósitos, porém o retorno ao país de origem esvazia de sentidos a passagem pelo exterior. Talvez por essa passagem ter sido, de fato, feita na 
"exterioridade" das sociedades em que viveram. E não foi por pouco tempo. Foram dez, dezoito, até vinte anos vividos nessa exterioridade.

Embora não represente a maioria, passei a testemunhar no CIATE as vicissitudes do retorno à origem. Ou, mais exatamente, as tentativas de retorno. Pois não há retorno possível. O país se transforma, a cultura ganha novos contornos, o trabalho muda, as tecnologias avançam, os adultos envelhecem, os adolescentes tornam-se adultos, as crianças crescem, os idosos morrem. Não há retorno no tempo. Eis o fator primeiro da profunda sensação de estranhamento dos emigrantes que voltam ao país de origem.

O emigrante que retorna sente-se estranho à família e os seus familiares também Ihe são estranhos. O "estranho familiar", como descreve Freud em sua obra, ${ }^{13}$ leva as angústias a picos imensuráveis pela falta de reconhecimento de si e do reconhecimento social, seja pelos familiares ou pelas comunidades de acolhimento. O estranhamento reverte-se em medo. Medo da cidade, medo das ruas, medo do trânsito, medo das pessoas, medo de entrar nas lojas, medo dos assaltos. Não que a cidade não seja violenta, mas o perigo é superdimensionado. Associados ao medo estão a aversão pela cidade, o trânsito, os coletivos, as pessoas e a cultura do lugar que era conhecido e lhes parece estranho.

Esta é a primeira dificuldade ${ }^{14}$ a se superar. Para superá-la, o acolhimento deve ser coletivo. A cidade, a comunidade, as entidades e as instituições precisam abrir espaços de acolhimento não só aos seus retornados como também aos imigrantes que chegam a todo o momento. $\mathrm{O}$ acolhimento pode ser de formas diversas, desde que se privilegie a circulação da palavra. Nesse caso, o atendimento em grupo realizado por técnico treinado na "escuta", 15 que possibilita ao participante colocar-se enquanto sujeito, cuja palavra vai além daqueles que o escutam. ${ }^{16}$

É surpreendente observar, no emigrante que retorna ao local de origem, o conceito que Freud chamou de "estranho familiar". Segundo ele, em certas ocasiões ocorrem coisas, impressões, experiências e situações que nos despertam sentimentos de estranheza em que o caráter assustador está relacionado justamente ao que é conhecido e que, no passado, era-nos muito familiar. Nesse sentido, observamos nos emigrantes que retornam

\footnotetext{
${ }^{13}$ FREUD, Sigmund. O estranho.

${ }^{14}$ Estou chamando de "dificuldade" o que poderíamos considerar como "sintomas" ou "transtornos", para não patologizar o processo de retorno. Pois, na maioria dos casos, trata-se de dificuldades transitórias, superáveis.

${ }^{15}$ Nesse caso, privilegio o psicanalista cuja escuta é específica.

${ }^{16}$ Quando o sujeito fala, fala para um grande Outro que está em si ou além do interlocutor, fazendo com que também escute o que diz. O grande Outro é o lugar dos significantes de onde a fala do sujeito é devolvida a ele. Nesse sentido, o sujeito, mesmo sozinho com o analista, confronta-se com o coletivo. Em grupo, esse grande Outro multiplica-se.
} 
a manifestação de estranhamento em relação ao ambiente, cultura, circunstâncias e pessoas que conheceram antes de partir para o exterior.

A estranheza remete-se ao "duplo", ou seja, uma instância que se forma com o próprio eu e que passa a exercer uma censura, observando e criticando o próprio eu. Dissociada do eu, como defesa ao risco do próprio aniquilamento, é projetada ao exterior como algo estranho a si. Então, os sentimentos de estranheza advêm do fato de o duplo ser uma criação em estádio primitivo do desenvolvimento mental. No colapso ou risco de colapso das defesas contra o aniquilamento do sujeito, o duplo emerge como algo estranho a si, causando-lhe medo e horror. Em vez de confusão mental, o sujeito mostra aversão a tudo o que o rodeia, levando-o a justificar uma nova emigração "por não se adaptar" na terra de origem. A noção do duplo também está na origem das formações paranoicas.

Observamos como o "retornado" investe contra as pessoas, os locais e a cultura de origem, tornando-se irritadiço e irritando seus familiares e amigos. Se um familiar faz uma pergunta qualquer, mesmo que seja ocasional com a finalidade de iniciar uma conversa, a indagação vai lhe parecer uma cobrança. Coisas assim: "O que você pretende fazer, agora que voltou?". Se um familiar perguntar se ganhou dinheiro, pode interpretar a interpelação como crítica e admoestação - do tipo: "Emigrou para quê, se não conseguiu ganhar dinheiro" - ou pode despertar-lhe sentimentos persecutórios: "Vão me pedir dinheiro" ou "Vão me roubar".

$\mathrm{Na}$ escuta psicanalítica, poderemos verificar que ele se refere a um "outro" ou "outros" que estão em si mesmo, e cobram-lhe resultados de seus atos e ações. Esse "outro" ou "outros" internalizados acabam sendo encarnados nos familiares, que também podem, de fato, encarnar os duplos, ao lhe cobrarem ações: "Mexa-se!", "Saia do quarto!", "Procure trabalho!". Coisas assim. Então, o "retornado" passa a ser duplamente cobrado: pelos familiares e pelo "outro" internalizado que pensa e age por si, como se fosse um estranho, o estranho familiar.

Uma das formas para sair dessas situações angustiantes é liberar a sua fala, real ou imaginária, a um outro ou outros da realidade cotidiana. Nesse sentido, a exposição de seus sentimentos e impressões sensoriais ao grupo mediado por alguém que o escuta além de suas palavras (o psicanalista) pode liberar a pressão, liberando o "outro" estranho internalizado. ${ }^{17}$ Liberada da

\footnotetext{
${ }^{17}$ No CIATE, mesmo não sendo exatamente um lugar de "escuta", ou seja, uma clínica psicanalítica, tenho recebido, no final das reuniões, manifestações de "Obrigado!" ou "Obrigada!" calorosos que representam o efeito que a palavra tem em si mesmos. Não significam cura dos males, mas um passo para o reencontro consigo mesmo.
} 
pressão do "outro" que estava retido em si, o retornado talvez possa ver, digamos, os brasileiros e a sua cultura sem tanto estranhamento e aversão.

Livres da pressão interna e o temor do que Ihes advém do exterior, os retornados poderão perscrutar melhor o ambiente que os envolve. Aconselho-os, então, a andar pela cidade, em primeiro lugar, pelos lugares que já conhecem, familiarizando-se com a nova situação. E também pelos locais que nunca frequentaram, locais de cultura, outras ruas, outros bairros que nunca visitaram quando moravam na cidade de origem, a fim de se apropriar dela como sujeito e como cidadão. Trata-se de um "andar pela cidade", mobilizado não pela força das angústias, mas pela necessidade de conhecimento e de reconhecimento. Em certos casos, isso não é possível sem atendimento ou acompanhamento prévio pelo profissional "psi" (psicólogo ou psicanalista), pois o estranhamento incorre ao medo - medo de circular sozinho, medo do trânsito, medo de tomar ônibus ou metrô, medo de assaltos -, à semelhança dos processos fóbicos.

Nos casos em que o nível de angústia ultrapassa os canais socialmente reguláveis, o sujeito sente a necessidade de se mobilizar constantemente. É levado a caminhar ou fazer coisas compulsivamente. Como não pode ficar "passeando" o tempo todo, opta pelo trabalho. "Qualquer trabalho", responde quando procura os agentes de recolocação no mercado. Os mais ativos conseguem a recolocação, porém, sem acompanhar a evolução do mercado de trabalho em seu país, ficam tecnologicamente defasados, além de, ao retornar, se encontrarem em faixas etárias consideradas fora do ciclo produtivo.

É bastante comum ouvir o argumento "não consigo ficar parado" para justificar a atividade, informal ou não, que não condiz com a sua cultura e capacidade intelectual. Depois de tentativas fracassadas para encontrar empregos melhores remunerados, o retornado acaba por aceitar trabalhos que não exigem qualificação. Contudo, o ambiente e os novos colegas de trabalho não apresentam o nível intelectual e cultural desejado fazendo com que opte por se manter isolado. Por não se interagir com o ambiente, a sua produtividade torna-se sofrível, levando à demissão. Mesmo quando se esforça e usa sua capacidade de trabalho, superando as dificuldades, não suporta a tensão e acaba por pedir demissão. O retornado "cava" a sua própria demissão.

A demissão, se de um lado lhe traz de imediato alívio na tensão, do outro aprofunda a baixa autoestima e a frustração. "Puxa! Nem este trabalho consigo fazer!" As tensões, os conflitos, o cansaço, o esforço pela longa jornada de trabalho e, principalmente, a humilhação no trabalho, ${ }^{18}$ eram suportáveis

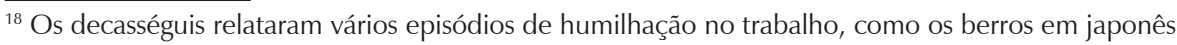


no Japão pelos altos ganhos salariais e pela ideia de que o sacrifício seria temporário, pois sempre haveria a possibilidade de "retornar para casa". No Brasil, para o retornado, as tensões, os conflitos e as frustrações justificam os novos deslocamentos. A experiência de trabalho no retorno pode durar poucos meses, mas os resultados de decepção e frustração são os mesmos.

Se o retornado não se esforçar pela qualificação e desenvolvimento de sua atuação, mesmo mantendo-se por longo tempo no mesmo emprego, a saída depois de dois ou três anos pode ser pior para conseguir nova recolocação. Pois nesse tempo teve aumentos salariais por dissídios coletivos e não vai poder trocar de emprego, na mesma função, mantendo os aumentos acumulados nesse período. Acostumados a trabalhar em plantas de fábricas no Japão, exercendo as mesmas funções, sem possibilidade de aprendizagem, qualificação e promoções, repetem a atitude no retorno.

Na maioria dos casos, é possível encontrar emprego formal com registro em Carteira de Trabalho. Difícil mesmo é mantê-lo empregado. Quando o retornado conseguiu fazer uma poupança que lhe permite sustentar-se por algum tempo sem trabalho ou conta com auxílio financeiro da família, por mínimo que seja, é aconselhável que ele se dê um tempo para a reflexão e a adaptação à nova situação e procure reciclar seus conhecimentos e habilidades profissionais. Não bastam, porém, os cursos rápidos de informática e outros que são geralmente oferecidos no mercado porque, embora necessários, não os habilitam ao de trabalho, pois ele não se apresenta exatamente como profissional. Se tiver uma profissão - por mais simples que seja - está totalmente defasado em relação aos colegas da área.

Este é um momento delicado: o momento em que o terapeuta avalia pela escuta o estado psíquico do sujeito, seu ambiente familiar, sua capacidade de ambientação e suas condições socioeconômicas. Poucas perguntas apenas para estimular a fala do sujeito - e muita escuta. É também uma opção difícil, mesmo que o retornado tenha economias, pois vai se sentir pressionado interna e exteriormente. Para começar, fica angustiado pelo fato de suas economias tão duramente acumuladas se esvaírem rapidamente, preferindo trabalhar para poupar os gastos. Nesse caso, acaba não tendo tempo para estudar e reciclar-se. Mesmo que conte com a compreensão e

que, mesmo não entendendo, eram-Ihes insuportáveis. Um deles, já na faixa dos 50 anos, que trabalhou carregando encanamentos em plantas de construção no período de altos ganhos salariais, informou o que Ihe era mais humilhantes: os "croques" (pequenas pancadas com os dedos indicador e médio dobrados) na cabeça, porque pela idade e constituição física não era tão rápido quanto os mais jovens. Mesmo assim, este senhor considera sua estada no Japão bem sucedida. Não mais retornou para lá (CARIGNATO, Taeco Toma. Passagem para o Desconhecido). 
apoio de familiares, qualquer pergunta, mesmo que seja apenas para iniciar uma conversa, transforma-se em cobrança. ${ }^{19}$

Os decasséguis ${ }^{20}$ que retornam geralmente evitam falar no dinheiro que ganharam no Japão, com medo de serem assaltados ou assediados por oportunistas e aproveitadores. Não se trata de um medo paranoico. Foram muitas as vítimas de assaltos no Brasil depois que a mídia passou a noticiar os altos ganhos dos trabalhadores brasileiros no Japão. Os nikkeys ${ }^{21}$, em geral, por razões ainda não esclarecidas, são muito vulneráveis a golpes de estelionatários. Eles evitam falar mesmo aos familiares que os acolhem, o que Ihes causa profundos conflitos, pois estes também não se encontram em condições econômicas confortáveis.

Mesmo nas condições difíceis dos familiares que os acolhem, aconselho-os a "segurar" ao máximo suas economias até conseguirem definir seus passos e visualizar sua trajetória passada e futura. A meu ver, nas condições de indefinição, insegurança e conflitos, tentar ajudar os familiares que permaneceram no país não vai ajudar a si mesmo ou à família. Melhor seria pensar, investir e concentrar-se na definição dos caminhos a percorrer. Em primeiro lugar, decidir se pretende se estabelecer no Brasil ou trabalhar no Japão, evitando o fenômeno da migração pendular.

Corto a palavra se ele disser: "Se der certo, fico no Brasil". É melhor que a procura de emprego parta da decisão de permanecer no país, pois então o retornado investirá nos meios de fixação, por mais difícil que seja a permanência no país de origem. Nada contra se decidir viver no Japão mesmo com as condições pessimistas da economia nipônica. Não deixarei de escutá-lo. O que importa é a escolha feita com base, como dizem os psicanalistas lacanianos, na identificação do desejo. É uma decisão difícil, essa de permanecer inativo com todas as pressões internas e externas. É necessário apoio psíquico, familiar e social para permanecer em uma situação cuja inatividade é apenas aparente pois, não dispondo de canais de escoamento dos estímulos, o seu interior torna-se ainda mais agitado.

O decasségui não fala sobre suas intenções, mesmo que tenha consciência de que o seu lugar é no Japão e precisa ficar algum tempo tempo indefinido - para resolver seus conflitos internos e se recuperar do

\footnotetext{
${ }^{19}$ Quando um amigo ou parente pergunta "O que você está fazendo?" parece-lhe que estão lhe dizendo que deveria estar trabalhando. Quando um familiar pergunta "Vai sair? Que horas volta?" parece-lhe ouvir: "Já que não está trabalhando, não deveria sair e gastar dinheiro por aí." Quando um colega de trabalho pergunta-lhe se é casado (a), se tem filhos, é invasão da vida privada, principalmente se o retornado (a) é solteiro (a).

${ }^{20}$ Nome que designava os trabalhadores migrantes sazonais, atribuído aos trabalhadores brasileiros no Japão.

${ }^{21}$ Pessoas de origem japonesa.
} 
desgaste físico e psíquico com as longas jornadas de trabalho em fábricas. Afirma que está procurando emprego, vai a algumas entrevistas e nunca é chamado para trabalhar. Ou fala em investir em negócio próprio, porém não define o que é "trabalhar por conta". Principalmente, fala de conflitos familiares constantes e confusos, a ponto de não ser possível identificar quem alimenta tais conflitos, se ele mesmo ou os familiares. São justificativas que busca para se convencer a voltar ao Japão.

O problema principal deste trabalho psíquico com os deslocados é a falta de sustentação institucional para a sua continuidade. No CIATE, obtive um espaço para atendimento esporádico e pontual. Não há possibilidade de atuação mais prolongada porque não se trata de uma entidade específica para cuidar das questões de saúde, principalmente as de saúde mental. Encaminhá-los aos serviços públicos de saúde mental traz outras consequências, pois tais serviços não contam com técnicos preparados para lidar com as questões de deslocamentos.

Acontece que, quando encaminhados aos serviços públicos, os retornados já se encontram com graves transtornos psíquicos. Nessas condições, correm os riscos da institucionalização, ou seja, os riscos de se perpetuarem como pacientes psiquiátricos. Isso Ihes deixa fortes marcas simbólicas portanto mais difíceis de serem eliminadas - do que genericamente se chama de loucura, marcas que são impressas socialmente no seu psiquismo. Como o retorno é marcado pelas instabilidades emocionais, indo da descarga psíquica por sair de uma situação penosa de insegurança no exterior às tensões em relação à nova situação no país de origem, os retornados podem ser vistos como estranhos em sua própria família. No ápice, quem seria o mais estranho dos estrangeiros no seio familiar, senão o doente mental?

\section{Atos que demandam simbolização}

Múltiplos são os exemplos de trabalhadores e trabalhadoras que retornam com sintomas psíquicos graves, como aconteceu com Tomika, e também com sintomas somáticos, como o caso de Cíntia, relatado pela pesquisadora Ana Luisa Campanha Nakamoto em sua dissertação de mestrado. ${ }^{22}$ Cíntia, casada, 26 anos, após seis anos de trabalho no Japão foi acometida com uma série de transtornos físicos - febre, vômitos, diarréias, dores e desmaios - com diferentes diagnósticos de médicos japoneses, de apendicite à infecção generalizada. Voltando ao Brasil, os sintomas desapareceram.

${ }^{22}$ NAKAMOTO, op. cit., p. 69 
Aos 17 anos, em 2000, ela e sua irmã Larissa, então com 18 anos, foram ao Japão para se encontrarem com a irmã mais velha, Mariana, 21 anos, que lá se encontrava desde 1995. Em casa, ficaram o pai, policial aposentado por invalidez, a mãe e o irmão caçula. Cíntia pretendia trabalhar por três anos, juntar dinheiro suficiente para comprar uma casa para os seus pais e estudar Direito. Determinou-se, logo no primeiro ano, a comprar um carro automático para o pai, fazendo sete horas extras todo dia. Saía às sete horas da manhã e retornava a uma hora do dia seguinte. Praticamente não dormia.

Em 2003, após três meses de namoro, foi morar com Renan, também brasileiro. Casou-se e, a partir daí, deixou de enviar dinheiro aos pais, passando a economizar para comprar um imóvel no Brasil, embora o casal não tivesse planos para retornar. No entanto, três anos depois, começaram os sintomas físicos que foram se agravando, obrigando-a a parar de trabalhar nos dois anos seguintes. Teve febre, vômitos, diarreia e dores em um lado da barriga. Levada ao hospital, um médico diagnosticou apendicite e indicou cirurgia.

No dia marcado para a cirurgia, outro médico a atendeu dizendoIhe que não tinha nada e poderia voltar ao trabalho. Porém, o mal-estar continuou e os colegas da fábrica comentaram que ela estaria com infecção. Cíntia passou a tomar "remédio contra infecção". Voltou ao hospital:

Aí no hospital falaram que tinha dado infecção generalizada (...) o pessoal da empresa falou: 'Está com glóbulos brancos altos, a Cíntia está com leucemia' (...) O médico japonês não sabia, toda vez ou queria me internar ou queria fazer uma cirurgia, ou ficava o dia todo no hospital e era liberada só à noite". (...) Mandavam fazer um monte de exames e não era nada... Não dava resultado nenhum. ${ }^{23}$

Como estava gastando muito dinheiro com consultas, remédios e táxi, resolveu retornar ao Brasil para se tratar. Chegando aqui, os sintomas desapareceram fazendo com que ela concluísse que o seu mal-estar era psicológico. Atribuiu-o ao excesso de trabalho, à tarefa repetitiva e ao silêncio na fábrica. Pensou em retomar seus planos de estudar e fixar-se no país. Mas deparou-se com as dificuldades de se inserir na sociedade brasileira, o que a colocou novamente na iminência do movimento pendular entre Brasil e Japão:

Então, eu não sei se eu volto, se eu fico... Eu queria ficar, mas meu marido não quer voltar para cá (...) eu queria na verdade ficar aqui. Mas já que meu marido não quer voltar, eu vou ter que voltar para lá. (...) Eu queria abrir um negócio aqui. Mas como caiu a produção lá, o medo é o meu marido ficar desempregado

\footnotetext{
${ }^{23}$ Depoimento a Nakamoto, op. cit., p. 68-69.
} 
lá. Então aí, eu também não quero voltar porque eu também não quero ficar desempregada lá. Para procurar emprego aqui no Brasil é difícil porque a minha Carteira de Trabalho... Eu fui com 17 anos, a minha Carteira de Trabalho está vazia, eu não tenho experiência nenhuma. Minha experiência é no Japão". ${ }^{24}$

Enquanto não decidia se ficava no Brasil ou voltava ao Japão, Cíntia fazia "bicos", ajudando em barraca de feira de conhecido, fazendo e vendendo salgadinhos. Novamente, empregos temporários. A justificativa é a mesma que se repete também com os outros retornados: Faz bicos "porque não gosta de ficar parada", não busca trabalho formal porque não tem experiência e as empresas exigem experiência registrada em Carteira de Trabalho. É nesta fase que Cíntia e muitos outros e outras deveriam receber atendimentos específicos para a reinserção na sociedade brasileira. Ela retornou ao país com 26 anos, jovem o suficiente para se qualificar profissionalmente, inclusive com curso superior, como era o seu sonho de adolescência.

Dificuldades maiores estão com os retornados na faixa etária de 50 e 60 anos. Muitos são aposentados e tiveram o cuidado de comprar um imóvel no Brasil. Mas aparecem aqueles que ainda precisam trabalhar para a sobrevivência. Já foram, pela idade e crise financeira, descartados do Japão e, aqui, a recolocação no mercado de trabalho torna-se quase impossível pelas condições psíquicas e pelas dificuldades em se adaptar à nova situação de "terceira idade". Parece que só se deram conta do envelhecimento quando, ao ficarem desempregados, foram obrigados a retornar ao Brasil. Mesmo os que possuem situação econômica estável - com aposentadoria e recursos economizados - procuram trabalho por "não conseguirem ficar parados em casa".

É a angústia que leva à atuação e a busca de trabalho também funciona como um ato que demanda a simbolização. ${ }^{25}$ Podemos perceber a atuação no diálogo que Nakamoto captou em uma instituição que atuava na recolocação do retornado no mercado de trabalho ${ }^{26}$ utilizando voluntários. A

${ }^{24}$ Ibidem, p. 69.

25 Atuação em psicanálise ocorre quando o sujeito coloca em prática ou ato para evitar a angústia, devido às dificuldades de verbalização e de simbolização. Em situação de análise (e mesmo fora dela), o sujeito substitui a verbalização pelo "agir" (acting out) para furtar-se à transferência. Lacan fez a distinção entre ato, acting out e passagem ao ato. Para ele, ato é sempre significante que permite a transformação do sujeito; Acting out é uma demanda de simbolização que o sujeito dirige ao analista; Passagem ao ato é o agir diante de uma situação ou fato não simbolizável, por meio do sujeito precipita-se em uma ruptura radical, como a agressão e o suicídio (ROUDINESCO, Elisabeth; PONTALIS, Michel. Vocabulário de Psicanálise). Nas situações que descrevo, tratam-se de atos significantes por meio dos quais os sujeitos podem chegar à simbolização.

${ }^{26}$ Instituto de Promoção Humana Grupo Nikkei atuou de 2000 a 2011 na recolocação dos retornados no mercado de trabalho em São Paulo. A forma equivocada de atuação centrava-se nas técnicas 
entidade recebeu um homem de mais de 50 anos, vestido com roupas velhas e sujas, falando de modo desarticulado, que foi atendido por uma voluntária. Segue-se trecho da entrevista:

Kenji (nome fictício): "Eu vim aqui porque preciso de um emprego..."

Yukie (nome fictício): "Entendo. E o que você fazia antes do Japão?"

Kenji: "Ah, eu... Dirigia um caminhão..."

Yukie: "Ah, sim. E você gostava disso?"

Kenji: "Ah, para mim era um emprego..."

Yukie: "E, em qual área você gostaria de trabalhar?"

Kenji: "Eu quero um trabalho."

Yukie: "Sim, mas em que área? Humanas? Exatas?"

Kenji: "Qualquer coisa. Só quero um trabalho. Vocês têm?"

Após algum tempo, Yukie levou-o a uma conversa particular. Mais tarde, contou à Nakamoto:

"Ele é uma pessoa com um problema muito grande de auto-estima. Eu peguei na mão dele e disse para ele olhar todo o dia no espelho e dizer que se ama, e mentalizar, sentir isso mesmo... É disso que ele precisa." 27

É um caso típico das entidades e pessoas de "bom coração" e com "boas intenções", porém sem nenhum preparo para atendimento a retornados. ${ }^{28}$ Segundo Nakamoto, Kenji saiu sem indicação de emprego. Nem de tratamento, eu acrescentaria. Ele era uma pessoa a ser encaminhada, em primeiro lugar, para um serviço de assistência social que investigaria suas condições sócio-econômicas, providenciando-lhe o auxílio básico necessário. Em seguida, ou ao mesmo tempo, aos serviços de saúde para um acompanhamento psicológico.

No atendimento aos retornados, assim como aos imigrantes e refugiados, é necessária escuta acurada que envolva conhecimentos sobre a política, a língua, a cultura e as experiências relacionadas a deslocamentos. Sem tais conhecimentos, pessoas com graves sintomas psíquicos como a Tomika e o Kenji podem ser confundidos como pacientes psicóticos e enclausurados em tais diagnósticos. Outros, como a Cíntia, passaram por situações

de auto-ajuda e no incentivo ao indivíduo para realizar seus projetos de vida com base na autoafirmação, determinação e planejamento. Sem buscar soluções políticas para o desemprego, funcionava como "ferramenta subjetiva de empoderamento na medida em que coloca ao alcance do indivíduo os requisitos necessários para a inserção profissional" (NAKAMOTO, op. cit. p. 61).

27 NAKAMOTO, op. cit., p. 60.

${ }^{28}$ Podemos pensar que a "colocação em ato" diante de uma situação que gera angústias também foi efetivada pela voluntária que atendeu o solicitante. 
críticas com riscos de intervenção cirúrgica desnecessária e medicalização incorreta. Podemos pensar que está aumentando, no Brasil, a ocorrência de casos semelhantes e mais graves ainda, principalmente quando se trata de refugiados de toda ordem: aqueles que fogem da violência, das catástrofes naturais e da miséria. ${ }^{29}$

A defesa dos direitos humanos envolve a área psíquica. Os profissionais da assistência de saúde e social dos serviços públicos devem passar além de sua condição de "agentes do Estado". Por ser descendente de japoneses e estar (parcialmente) inserida na comunidade nipo-brasileira, posso me considerar profissional "orgânica", o que facilita a transferência. Digo parcialmente porque não funciono como "agente" das instituições com as quais atuo. Talvez essa transferência seja possível até por não compartilhar dos métodos, pensamentos e ideologias a respeito de trabalho, migrações, assistência, política e cultura dos meus pares nipo-brasileiros. Basicamente, poderia me definir como diferente entre meus iguais (nipo-brasileiros) e igual entre os diferentes (brasileiros), tal qual o retornado.

$\mathrm{O}$ atendimento fundamentado na elaboração da transferência e da escuta permite que os retornados - poderia acrescentar os imigrantes e os refugiados - recuperem e usem os seus recursos simbólicos e possam expressar-se por diferentes vias que não sejam as dos sintomas psíquicos, somáticos ou de atuações em constantes deslocamentos físicos e geográficos, mesmo em deslocamentos psíquicos, por meio de delírios e alucinações. Podemos entender os sintomas persecutórios de Tomika e os sintomas somáticos de Cíntia como resultados de situações e sofrimentos que não lhes faziam sentido por estarem bloqueados pela ausência de canais de expressão.

Outros recursos que não os psicoterapêuticos poderão ser explorados e desenvolvidos para que os retornados e outros diferentes encontrem suas diversas vias expressivas simbólicas, como por exemplo, as artes em suas diferentes ramificações. As artes, ricas formas de manifestações psíquicas e corporais, parecem estar ausentes no processo migratório decasségui, totalmente voltado para suprir as fendas tecnológicas que as máquinas não conseguem preencher. No extremo, os trabalhadores imigrantes "tampões" quando retornam, retornam no real. ${ }^{30}$

\footnotetext{
${ }^{29}$ Têm aumentado, na Casa do Migrante, em São Paulo, casos que exigem atendimento integrado que o nosso sistema público de saúde mental não dá conta.

${ }^{30}$ Conceito lacaniano: o que não é simbolizado retorna no real, como delírios e alucinações que causam repulsa e horror.
} 


\section{Bibliografia}

CARIGNATO, Taeco Toma. Passagem para o Desconhecido. Um estudo sobre as migrações entre Brasil e Japão. São Paulo: Via Lettera, 2002.

CIATE - Centro de Informação e Apoio aos Trabalhadores no Exterior. Vinte anos de História. São Paulo: CIATE, 2012.

FREUD, Sigmund, A dinâmica da transferência. Obras Completas, Volume XII. Rio de Janeiro: Imago, 1969 [1912]. [1919].

. O estranho. Obras Completas. Volume XVII. Rio de Janeiro: Imago, 1969

Recomendações aos médicos que exercem a psicanálise. Obras Completas, Volume XII. Rio de Janeiro: Imago, 1969 [1913].

LACAN, Jacques. A direção do tratamento e os princípios do seu poder. In Escritos. Rio de Janeiro, Jorge Zahar, 1998 [1958].

. As psicoses. Livro 3. Rio de Janeiro: Jorge Zahar, 1988 [1955-1956].

NAKAMOTO, Ana Luisa Campana. De volta para casa: um estudo sobre brasileiros e brasileiras retornados do Japão. Dissertação de mestrado em Sociologia, apresentado na Faculdade de Filosofia, Letras e Ciências Humanas da Universidade de São Paulo. São Paulo, 2012.

ROUDINESCO, Elisabeth; PLON, Michel. Vocabulário de Psicanálise. Rio de Janeiro: Jorge Zahar, 1998.

\section{Abstract}

\section{The construction of a psychoanalyticclinic for migrants}

The objective of this article is to develop a clinical methodology that involves the history and policy regarding tending to people and groups in movement, who marked by deep ruptures and other traumatic experiences. It debates the psychosocial approach that privileges psychoanalysis directed not only to emigrants and immigrants, as well as to thosecalled "returned", particularly the dekassegui, whose reinsertion in their country of origin is made difficult by the state of social and cultural "suspension" in which they are insertedin due to the comings and goings between their country of origin and that of immigration. The article also aims to investigate the several paths followed to develop and symbolize the traumatic experiences of human displacement.

Keywords: Dekassegui; Returned; Tending; Psychoanalysis; Trauma.

Recebido para publicação em 26/02/2013.

Aceito para publicação em 13/05/2013.

Received for publication in February, 26 ${ }^{\text {th }}, 2013$.

Accepted for publication in May, 13 2013. 